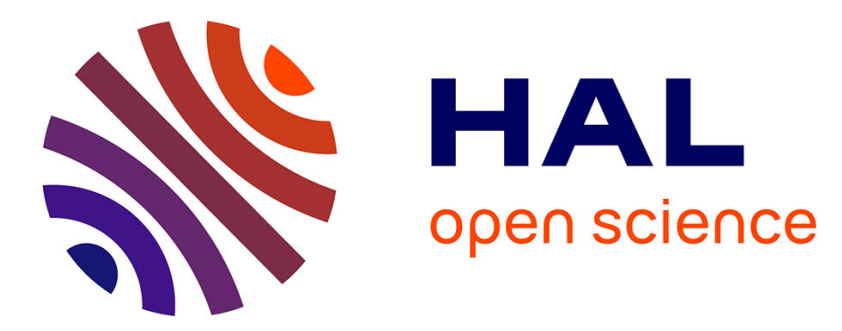

\title{
Cage-shaped Wideband Antenna Based on Folded Monopoles
}

Christophe Morlaas, Bernard Souny, Alexandre Chabory

\section{To cite this version:}

Christophe Morlaas, Bernard Souny, Alexandre Chabory. Cage-shaped Wideband Antenna Based on Folded Monopoles. ISAP 2014, International Symposium on Antennas and Propagation, Dec 2014, Taiwan, Taiwan. hal-01060866

\section{HAL Id: hal-01060866 \\ https://hal-enac.archives-ouvertes.fr/hal-01060866}

Submitted on 4 Sep 2014

HAL is a multi-disciplinary open access archive for the deposit and dissemination of scientific research documents, whether they are published or not. The documents may come from teaching and research institutions in France or abroad, or from public or private research centers.
L'archive ouverte pluridisciplinaire HAL, est destinée au dépôt et à la diffusion de documents scientifiques de niveau recherche, publiés ou non, émanant des établissements d'enseignement et de recherche français ou étrangers, des laboratoires publics ou privés.

\section{(ㅇ)(1) $\$$}

Distributed under a Creative Commons Attribution - NonCommercial - NoDerivatives| 4.0 


\title{
Cage-shaped Wideband Antenna Based on Folded Monopoles
}

\author{
Christophe Morlaas*, Bernard Souny ${ }^{\dagger}$, Alexandre Chabory* \\ *TELECOM/EMA, ENAC, Toulouse Univ. 7 av E. Belin, 31055 Toulouse, France. (morlaas@recherche.enac.fr) \\ $\dagger$ Associate researcher at TELECOM/EMA, ENAC
}

\begin{abstract}
A new antenna structure based on a disk-loaded folded monopole antenna is presented. Its VSWR performances are equivalents to thus of the Goubau antenna for similar dimensions. The radiation pattern is monopole-like on the full bandwidth (one octave) and the manufacturing is very easy.

The operation analysis based on a basic loaded folded monopole is presented and validated from a full-wave simulation tool.

Index Terms-Compact antenna, wide bandwidth, Goubau antenna, loaded monopole.
\end{abstract}

\section{INTRODUCTION}

In many applications, monopole-like pattern is required and equivalent structures have been extensively studied. A good candidate for this is the disk loaded folded monopole [1] and a well known type of such a wide bandwidth miniaturized monopole is the antenna proposed by G. Goubau [2]. However the manufacturing is complex. Others modified versions have been proposed by different authors with similar VSWR performances but they not fill-full all requirements, bandwidth, size and pattern.

In this paper we present a new type of disk-loaded folded monopole and we explain the design of this cage-shaped antenna. With similar dimensions as a Goubau antenna we obtain the same VSWR bandwidth, the radiation pattern remains quasi circular in the upper part of the bandwidth. In addition manufacturing is very easy.

The section II describes the antenna design and operation based on the equivalent circuit of a loaded folded monopole with the important points that affect the antenna design. The section, III presents the relevant characteristics of this antenna.

\section{ANTENNA DESCRIPTION}

A picture of this antenna is given Fig. 1. The antenna is intended to be used on a metallic roof so for simulation purpose the antenna is over an infinite perfect electrical (IPEC) conductor. During conception process we use idealized model to accelerate simulation, perfect conductor and disc infinitely thin.

\section{A. Folded Monopole analysis}

The general idea is based on the operation of a folded monopole. Equivalent circuit of a disk-loaded folded monopole are given in [3]. This analysis is based on the current decomposition in two different modes : an unfolded monopole mode (even mode) that it can be approximated by several

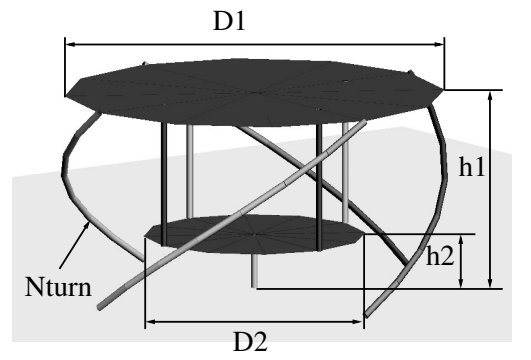

Fig. 1. Monopole antenna with quadrifilar cage (section II): $h 1=5.5 \mathrm{~cm}$ $h 2=1.5 \mathrm{~cm}, D 1=12 \mathrm{~cm}, D 2=7 \mathrm{~cm}$, Wire diameter $2 \mathrm{~mm}$, Nturn $=$ .25

series resonant circuits, and a transmission line mode (odd mode) that it can be approximated by a shunt resonant circuit. At the antenna input port, The impedance $\left(Z_{a}\right)$ is the one of the transmission line $\left(Z_{t l}\right)$ in parallel with the one of the unfolded disk-load monopole impedance $\left(Z_{u m}\right)$ via an impedance transformer $(\eta)$.

The transformer ration depend on the current driven in the excited wires compare to the current in others wires. It can be adjusted with the relative diameter between the excited wire and others.

With this equivalent scheme the direct effect of the geometry on the input reflection coefficient and the antenna operation can be easily analyzed.

\section{B. Antenna design and operation}

The general idea is to design a folded monopole of stepped design. The first mode (mode 1) corresponding to the upper frequency resonator, is constituted from the top to bottom : an upper disc (TD) of $D 1=12 \mathrm{~cm}$, a central conductor (IW) built with four spaced wires of $7 \mathrm{~cm}$ of $d=2 \mathrm{~mm}$ diameter and of $40 \mathrm{~mm}$ length, a bottom disc (BD) of $D 2=7 \mathrm{~cm}$ and the feeding wire (FW) between the bottom disc and the metallic plane plus four wires (OW) connecting the (TD) to the bottom metallic plane to complete the folded structure.

The effective diameter of the central conductor can be used to tune as well the proper operating frequency as the impedance matching.

To increase the bandwidth, the transmission line mode (mode 2) appear from the added four helical wires (OW) linked between the top disc and the metallic plane. The frequency of this mode can be tuned from the length of this wires. This 
mode extends toward low frequency the useful bandwidth of the antenna.

Nevertheless it exist a $3^{\text {th }}$ mode which is an upper mode of the mode 1 . This both modes are then difficult to tune independently and the radiation of this mode can disturb the mode 2 (see III).

\section{Input reflexion coefficient}

The large diameter of (IW) is proper to decrease $Z_{u m}$ to obtain a $50 \Omega$ impedance considering a proper $Z_{t l}$ through the length of (OW) (see II-C). Finely, we use four spaced wires to build the central conductor (IW) easily. if only one thin wire connecting the top disk to ground is used, the short circuited transmission line is:

- too short, then, the disk load efficiently the monopole but not the transmission line mode.

- have an characteristic impedance too high to give an effective compensation with a large center conductor (IW).

A solution to lower characteristic impedance is to have a greater number of wires connecting the top disk to ground (here 4 are used). To lengthen the line we can use different solutions: a portion of helix, a mender line section, a solenoidal section (here the first one is used as shown in Fig. 1).

\section{ANTENNA PERFORMANCES}

It can be shown in Fig. 2 the gain performances for lower, central and upper frequency in the bandwidth. As reported in [2] the radiation pattern undulations increases with the frequency. These undulations come from the wire currents of the outer wires (OW). This currents can be seen like Diracs which excite the spatial harmonics varying on $e^{N_{b} j \phi}$ where $N_{b}$ is the wires number and $\phi$ a rotational angle. For low frequency, these harmonics cannot radiate because they are under there cutoff radius $\left(\simeq N_{b} \lambda / \pi\right)$. But the higher the frequency is, the more they radiate. Beside, the gain is lightly decreased because the frequency of the third mode is became lower and it begin to radiate.

The corresponding reflexion coefficient is given in the Fig. 3. We obtain an octave bandwidth at VSWR=2.

The wire winding around the $D 1$ diameter presents some drawback on the polarization quality. This solution introduce a coupling between the co and the cross-polarization modes ( $T M_{01}$ and $T E_{01}$ modes). we obtain a cross-polarization ratio of about $-25 \mathrm{~dB}$ as shown in the Fig. 4.

\section{CONCLUSION}

The new antenna structure presents VSWR performances very similar to the ones of the Goubau antenna (one octave bandwidth).

The operation analysis is based on the mode decomposition of a basic loaded folded monopole and allow an easy understanding of the antenna operating. Unlike Goubau antenna, the radiation pattern stay uniform in the high part of the bandwidth. Manufacturing of this antenna is easy and can be done economically with plates and wires thanks to the low sensitivity to the dimensions accuracy.

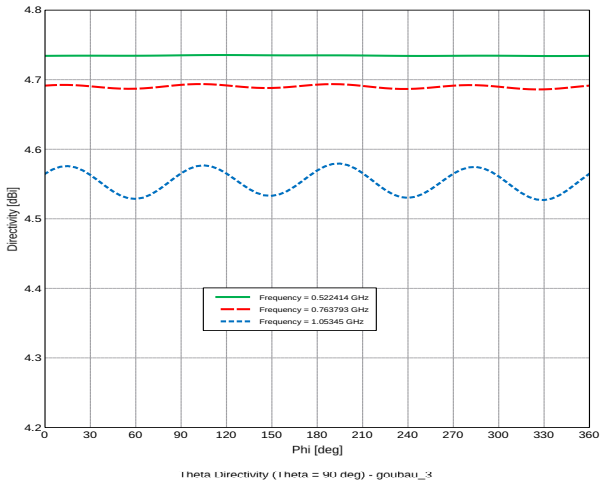

Fig. 2. Azimuthal gain (dB) of for lower (green solid line), central (red dashed line) and higher (blue dotted line) frequencies at $\theta=\pi / 2$.

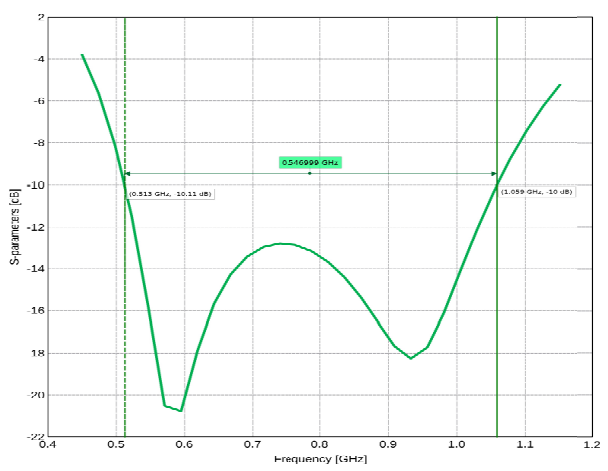

Fig. 3. Reflexion coefficient for the four wires antenna between $450 \mathrm{MHz}$ and $1.15 \mathrm{GHz}$.

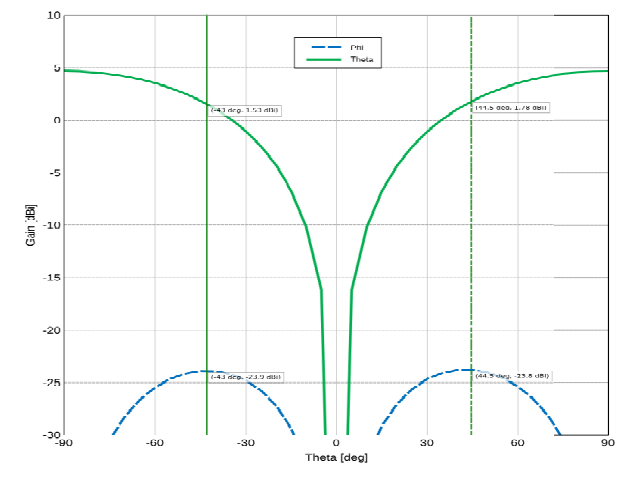

Fig. 4. Co and cross polarization at $0.76 \mathrm{GHz}$ and $\phi=0 \mathrm{deg}$.

\section{REFERENCES}

[1] E. W. Seeley, "An experimental study of the disk-loaded folded monopole," IRE Trans. Antennas Propagat., vol. AP-4, p. 27-28, Jan. 1956.

[2] G. Goubau, "Multi-element monopole antennas," (the first published ECOM-ARO description of the sectored disk monopole) Proc. Workshop on Electrically Small Antennas, Fort Monmouth. NJ, May 6 and 7, 1976, G. Goubau and F. K. Schwering, Eds. pp. 63-67.

[3] H.Foltz, J.S.McLean, L.Bodner, "Closed-Form Lumped Element Models for Folded, Disk-Loaded Monopoles", A.P. International symposium 2002 pp 576-579 